\title{
Human Papillomaviruses in Buschke-Löwenstein Tumors: Physical State of the DNA and Identification of a Tandem Duplication in the Noncoding Region of a Human Papillomavirus 6 Subtype
}

\author{
MICHAEL BOSHART AND HARALD ZUR HAUSEN* \\ Deutsches Krebsforschungszentrum, D-6900 Heidelberg, Federal Republic of Germany
}

Received 10 January 1986/Accepted 3 March 1986

\begin{abstract}
Six Buschke-Löwenstein tumors, i.e., highly differentiated squamous cell tumors of the genital region, were shown to contain human papillomavirus 6 (HPV 6) or HPV 11 genomes. The viral DNA was found in an episomal state, including a very small fraction of circular oligomers. HPV 6a and HPV 6d genomes were cloned from two of the tumors. Comparison with HPV 6b, cloned from a benign genital wart (E.-M. de Villiers, L. Gissmann, and H. zur Hausen, J. Virol. 40:932-935, 1981) by restriction mapping and partial sequence analysis, revealed a very high degree of homology with the different HPV 6 subtypes. A tandem duplication of 459 base pairs within the noncoding region of the genome was found in the new subtype HPV 6d. This structural rearrangement in a region containing the putative control elements for early gene transcription might influence the biological potential of that virus. No evidence for rearrangement of this region was found in the HPV DNA from the five other tumors.
\end{abstract}

It is well established that benign genital warts (condylomata) are caused by human papillomaviruses (HPV): HPV type 6 (HPV 6) or HPV 11 can be detected in over $90 \%$ of these lesions $(9,12)$, and very recently, it has been shown that in vitro infection of human cervical tissue explants with these HPV types elicited a histological picture typical for genital warts (14). Buschke-Löwenstein tumors or giant condylomata are large verrucous genital tumors which do not metastasize (2), but clinically they are nevertheless regarded as malignant (8). Histologically, they share many features with condylomata acuminata, but ultrastructurally, they show some Bowenoid features (13). It has been suggested that the Buschke-Löwenstein tumor might be an intermediate lesion within a continuous spectrum of biologically related tumors ranging from the condyloma to the invasive squamous cell carcinoma $(4,17)$. Malignant genital tumors and preneoplastic lesions are strongly associated with HPV 16 and HPV 18, whereas HPV 6 and HPV 11 seem to be mostly confined to benign condylomatous lesions $(1,6$, 11). Exceptions seem to exist, however, as HPV 6 or HPV 11 DNA has been detected in a few Buschke-Löwenstein tumors analyzed earlier $(9,15)$ and in six tumors reported in this communication. Consequently, Buschke-Löwenstein tumors and condylomata were analyzed for differences in the structure or the physical state of HPV 6 and HPV 11 DNA possibly linked to the biological properties of the corresponding lesion.

Genomic DNA from six Buschke-Löwenstein tumor biopsies was subjected to Southern blot hybridizations with cloned HPV 6, HPV 11, HPV 16, and HPV 18 as probes. Extraction of genomic DNA from tumor tissue, gel electrophoresis and transfer, labeling of DNA, and hybridization conditions for high and low stringency were done exactly as described previously (1). All tumor DNAs were positive for HPV 6 or HPV 11 sequences under highstringency conditions $\left(T_{m},-18^{\circ} \mathrm{C}\right)$. The typical $P s t$ I cleavage patterns of HPV 6 and HPV 11 (12) and differential reactivity

\footnotetext{
* Corresponding author.
}

with the HPV 6 and HPV 11 probes (not shown) allowed precise typing (Fig. 1). No additional signals were detected when hybridizing under low-stringency conditions $\left(T_{m}\right.$, $-40^{\circ} \mathrm{C}$ ) with HPV 6 DNA (Fig. 1) or under high- and low-stringency conditions with HPV 16 or HPV 18 DNA (data not shown). Thus, it can be ruled out that the additional presence of HPV 16 or HPV 18 within a primarily benign HPV 6- or HPV 11-containing condyloma is responsible for the more agressive growth properties of the BuschkeLöwenstein tumors. One tumor (Fig. 1, lane 5) contained a new subtype of HPV 6 with a slightly larger genome (HPV $6 d)$.

The physical state of HPV DNA was then analyzed in five Buschke-Löwenstein tumors. After digestion of genomic DNA with a one-cut restriction enzyme for HPV 6 and HPV 11 , a single band could be visualized by Southern blot hybridization, corresponding to linearized, 8-kilobase HPV genomes (Fig. 2). The typical pattern of forms I, II, and III of free episomal HPV genomes was visible in all tumor DNAs after digestion with different noncut enzymes. Very faint additional bands could be detected in the highmolecular-weight region of the gel. They were, however, identified as circular oligomers, as their size was identical in all tumors; they disappeared completely after digestion with a one-cut enzyme, and they could not be mobilized by different noncut enzymes that are known to cleave frequently within the human genome (Fig. 2). Thus, there was no evidence for integration of viral sequences in the Buschke-Löwenstein tumors investigated here.

The identification of a HPV 6 subtype with a larger genome in one biopsy (HPV 6d; Fig. 1, lane 5) led to a careful comparison of HPV 6 DNAs from BuschkeLöwenstein tumors and benign condylomata. Therefore HPV 6a and HPV 6d were cloned from the DNAs of two tumors (Fig. 1, lanes 3 and 5, respectively). The viral DNAs were first isolated from genomic libraries constructed in phage vectors $\lambda \mathrm{L} 47$ or EMBL 3, as described by Gissmann et al. (10), and were then subcloned into pBR322. HPV 6b had previously been cloned from a condyloma acuminatum 


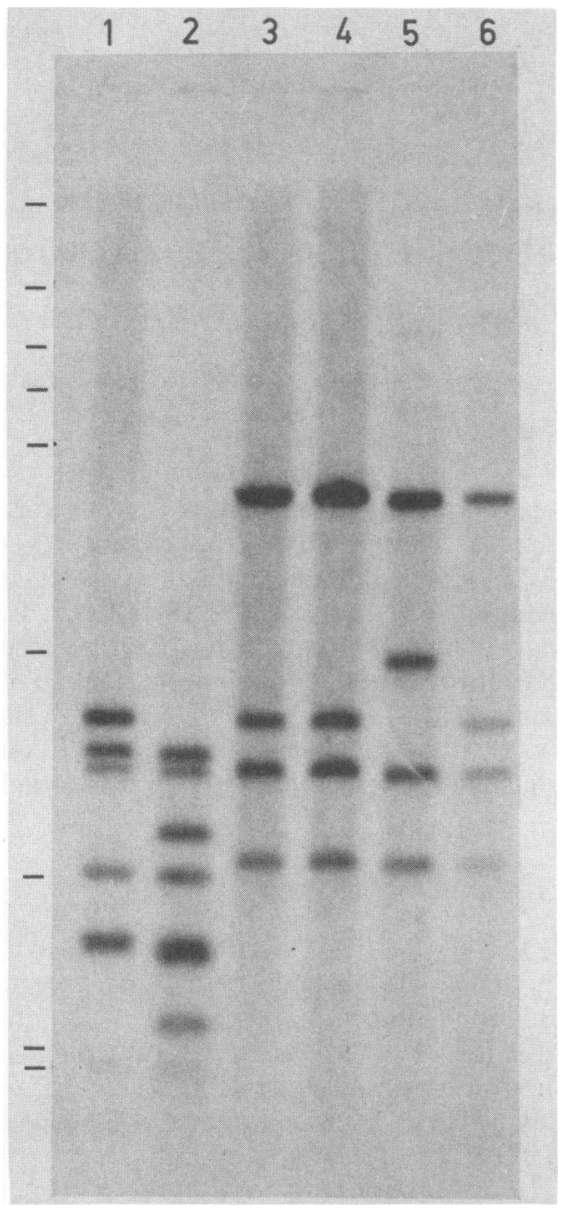

FIG. 1. Typing of HPV DNA in six Buschke-Löwenstein tumors. Genomic DNA was cut with PstI, separated in $1 \%$ agarose gels, transferred to a nitrocellulose filter and hybridized under low-stringency conditions $\left(T_{m},-40^{\circ} \mathrm{C}\right)$ with a nick-translated ${ }^{32} \mathrm{P}$ labeled HPV $6 \mathrm{~b}$ probe. The amount of DNA loaded per slot $(2$ to 20 $\mu \mathrm{g})$ was adjusted to get comparable signals in all lanes. The PstI cleavage patterns allowed distinction of different HPV 6 and HPV 11 subtypes (12). Lanes: 1, HPV 11a; 2, HPV 11c; 3, HPV 6a; 4, HPV 6a; 5, HPV 6d; 6, HPV 6a. A mixture of $\lambda$ HindIII-fragments and PM2 HindIII-fragments was used as markers $(23.7,9.64,6.64,5.64$, $4.33,2.15,1.04,0.48$, and 0.44 kilobases). Note the size difference between the PstI B fragments of HPV 6a (lanes 3, 4, and 6) and HPV $6 \mathrm{~d}$ (lane 5) due to the tandem duplication of $459 \mathrm{bp}$ within the HPV 6d genome (Fig. 3).

(5) and sequenced (18). The genomes of the three cloned HPV 6 subtypes were linearized by BamHI cleavage, gel purified from the vector sequences, and subjected to restriction analysis with 13 different endonucleases, thus probing for differences at 27 cleavage sites predicted by the HPV $6 \mathrm{~b}$ sequence. HPV $6 \mathrm{~b}$ and HPV $6 \mathrm{~d}$ differed at only 1 of the 27 sites, HPV 6a and HPV 6d differed at 3 sites, and HPV 6a and HPV $6 \mathrm{~b}$ differed at 4 sites, thus reflecting a very high similarity of the HPV 6 subtypes (data not shown). The size difference of HPV $6 \mathrm{~d}$ relative to HPV $6 \mathrm{a}$ (Fig. 1) was attributable to the insertion of about 460 base pairs (bp) within the noncoding region of the HPV $6 \mathrm{~d}$ genome. For further analysis of that insertion, the cleavage sites of a number of frequently cutting restriction enzymes were mapped within the PstI B fragments of HPV 6a and HPV 6d. These maps were compared with the corresponding part of the HPV $6 \mathrm{~b}$ genome, which includes the noncoding region.
The data confirmed conservation of almost all restriction sites among subtypes and suggested duplication of about 460 bp within the noncoding region of HPV 6d (Fig. 3). This part of the noncoding region of HPV $6 \mathrm{~d}$ was then sequenced by the chemical method of Maxam and Gilbert (16), and an exact tandem duplication of $459 \mathrm{bp}$, encompassing more than half of the noncoding region, was found (positions 7528 to 84 [18]; Fig. 3). The sequence information obtained for HPV 6d (a total of $634 \mathrm{bp}$ ) diverged only by two point mutations from the HPV $6 \mathrm{~b}$ sequence (position 7585, $\mathrm{A} \rightarrow \mathrm{C}$; and position $7815, \mathrm{G} \rightarrow \mathrm{C}$ ). This underscores the high sequence homology among HPV 6 subtypes. The FnuDII/HinfI fragment spanning part of the noncoding region most proximal to the L1 open reading frame was found to be about $120 \mathrm{bp}$ larger in HPV $6 a$ and HPV $6 d$ than was predicted by the HPV $6 \mathrm{~b}$ sequence. The significance of this finding was questionable, as rearrangements within the same fragment had frequently been observed during the cloning procedures. To clarify this point, a number of condylomata acuminata and BuschkeLöwenstein tumors were reanalyzed, including the materials from which HPV 6a, HPV 6b, and HPV 6d had been cloned. The genomic DNAs were digested with HinfI and subjected to Southern blot analysis with a subgenomic fragment (PstI B) of HPV 6 as probe, which covers the noncoding region. As a result, no differences could be detected between restriction fragments from the late side of the noncoding regions of the HPV $6 \mathrm{a}, \mathrm{HPV} 6 \mathrm{~b}$, and HPV $6 \mathrm{~d}$ genomes in tumors and condylomata and the corresponding fragments of the cloned HPV 6a and HPV 6d DNA (data not shown). The HPV 6 b clone pAmp2 used for sequence analysis of that region by Schwarz et al. (18) was, however, shown to bear a deletion of about $120 \mathrm{bp}$ (Fig. 3). This part of the genome is very rich in alternating purine-thymidine nucleotides and thus, cloning in Escherichia coli may result in deletions by recA-independent recombination of short direct sequence repetitions, according to a model proposed by Collins et al. (3).

The presence of HPV 6 or HPV 11 and the episomal state of the viral genomes clearly distinguish Buschke-Löwenstein tumors from invasive genital carcinomas, which mostly harbor integrated copies of HPV 16 or HPV 18 DNA $(1,6$, 7). The tandem duplication of $459 \mathrm{bp}$ within the noncoding region of HPV $6 \mathrm{~d}$ is of considerable interest as it duplicates the putative control elements and start sites for early gene transcription. Enhanced or deregulated early gene expression might be the consequence and could confer a higher tumorigenic potential to a virus which usually induces benign tumors (condylomata). A similar mechanism has been evidenced for human papovavirus BK: in a number of BK virus mutants which transform rodent cells much more efficiently than wild type $\mathrm{BK}$, sequence rearrangements affecting the viral enhancer (68-bp repeat) within the noncoding region of the genome have been found (19). These rearrangements are responsible for the phenotype of the mutants $(19,21)$, and, as far as was analyzed, deregulated, continuous expression of early gene functions of the mutant genomes was observed (20). There was no evidence for structural alterations in the noncoding region of the viral genomes from any other of the six Buschke-Löwenstein tumors. Thus, in many cases host factors, rather than the occurrence of specifically pathogenic viral variants, might account for the rare development of a Buschke-Löwenstein tumor as the final stage of a long-persisting genital infection with HPV 6 or HPV 11. Impairment of cell-mediated immunity, as well as the synergistic action of carcinogenic factors, may play a role, as has been suggested for the development 


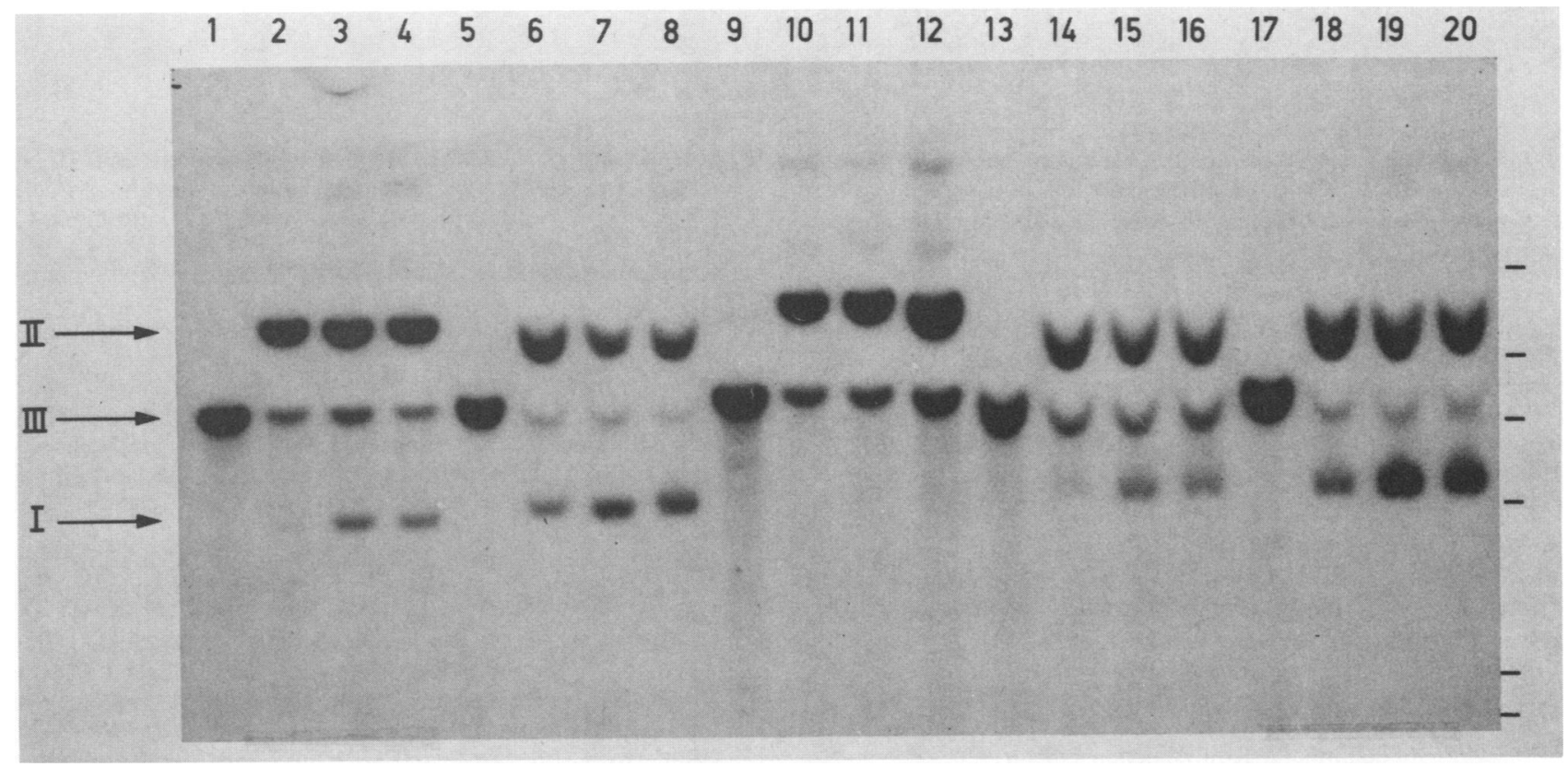

FIG. 2. Physical state of HPV DNA in Buschke-Löwenstein tumors. Genomic DNA of five tumors was digested with BamHI (lanes, 1, $5,9,13$, and 17), BclI (lanes 2, 6, 10,14, and 18), BglII (lanes 3, 7,11, 15, and 19), or SstI (lanes 4, 8, 12, 16, 20), separated in a 0.5\% agarose gel, transferred to a nitrocellulose filter, and hybridized under stringent conditions with nick-translated ${ }^{32}$ P-labeled HPV 6d DNA. Lanes 1 through 4 HPV 11c DNA; lanes 5 through 8, HPV 11a DNA; lanes 9 through 12, HPV 6d DNA; lanes 13 through 16 HPV 6a DNA; lanes 17 through 20, HPV 6a DNA. The positions of nicked circles (form II), linear molecules (form III), and covalently closed circles (form I) are indicated by arrows. The amount of form I was low after digestion with BclI, due to a nicking activity in this enzyme preparation. $\lambda$ HindIII fragments were used as markers.

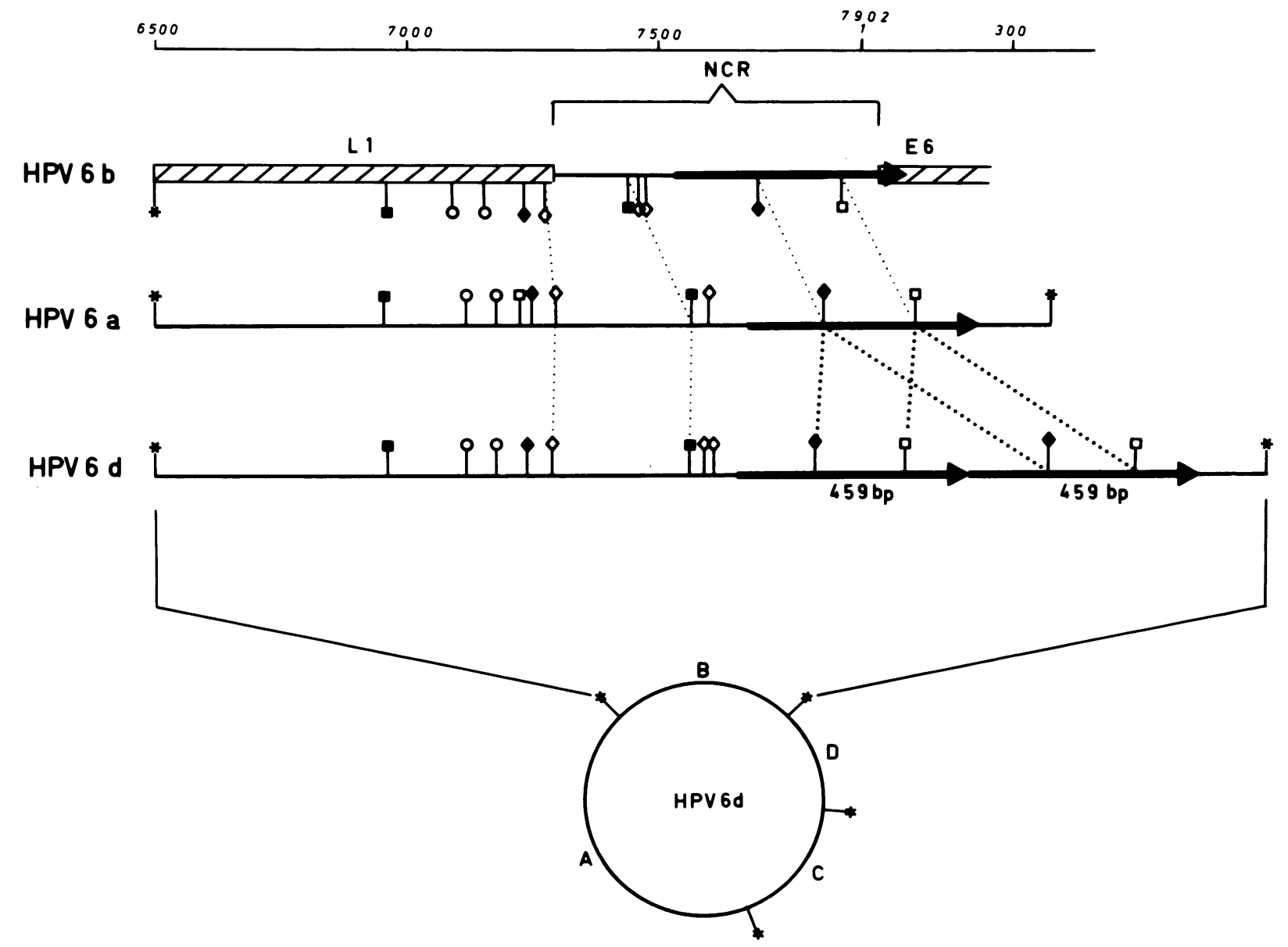

FIG. 3. Restriction maps of the PstI B fragments of HPV 6a and HPV 6d in comparison to the restriction map of the corresponding region of HPV $6 \mathrm{~b}$ as compiled from the sequence of Schwarz et al. (18). The open reading frames L1 and E6 of HPV $6 \mathrm{~b}$ are indicated by hatched boxes, and the noncoding region between L1 and E6 is emphasized by a bracket. The scale at the top of the figure gives the nucleotide positions of HPV $6 \mathrm{~b}$. The tandem duplication of $459 \mathrm{bp}$ in HPV $6 \mathrm{~d}$ and the homologous sequence in HPV $6 \mathrm{~b}$ are marked by arrows. The corresponding segment of HPV 6a is also indicated, but has not been sequenced. Below, the PstI B fragment is shown as part of the circular genome of HPV 6d. Sites: FnuDII $(\diamond)$, HaeII $(\diamond)$, HinfI $(\square)$, HpaII $(\square)$, PstI $(*)$, Sau3A (O). 
of cervical cancer (22). Lack of hygiene, long persistence of genital HPV infection and inappropriate treatment have repeatedly been pointed out as risk factors for BuschkeLöwenstein tumors $(8,13)$.

We thank L. Gissmann for critical reading of the manuscript, $M$. Dürst for probing of tumor DNAs for HPV 16 sequences, G. Schütz for support, and H. Rühl and M. Cole for excellent secretarial work.

This work was supported by the Deutsche Forschungsgemeinschaft (SFB 31: Tumorentstehung und -entwicklung), and part of it was done at the Institut für Virologie, Universität Freiburg, Federal Republic of Germany.

\section{LITERATURE CITED}

1. Boshart, M., L. Gissmann, H. Ikenberg, A. Kleinheinz, W. Scheurlen, and H. zur Hausen. 1984. A new type of papillomavirus DNA, its presence in genital cancer biopsies and in cell lines derived from cervical cancer. EMBO J. 3:1151-1157.

2. Buschke A., and L. Löwenstein. 1925. Uber carcinomähnliche Condylomata acuminata. Klin. Wochenschr. 4:1726.

3. Collins, J., G. Volckaert, and P. Nevers. 1982. Precise and nearly- precise excision of the symmetrical inverted repeats of Tn5; common features of recA-independent deletion events in Escherichia coli. Gene 19:139-146.

4. Dawson, D. F., J. K. Duckworth, H. Bernhardt, and J. M. Young. 1965. Giant condyloma and verrucous carcinoma of the genital area. Arch. Pathol. 79:225-231.

5. de Villiers, E.-M., L. Gissmann, and H. zur Hausen. 1981. Molecular cloning of viral DNA from human genital warts. J. Virol. 40:932-935.

6. Dürst, M., L. Gissmann, H. Ikenberg, and H. zur Hausen. 1983. A papillomavirus DNA from a cervical carcinoma and its prevalence in cancer biopsy samples from different geographic regions. Proc. Natl. Acad. Sci. USA 80:3812-3815.

7. Dürst, M., A. Kleinheinz, M. Hotz, and L. Gissmann. 1985. The physical state of human papillomavirus type 16 DNA in benign and malignant genital tumours. J. Gen. Virol. 66:1515-1522.

8. Friedman-Kien, A. E. 1976. Giant condyloma of BuschkeLöwenstein, p. 814-820. In R. Andrade, S. L. Gumport, G. L. Poplin, and T. D. Rees (ed.), Cancer of the skin, vol. 1. Biology-diagnosis-management. The W. B. Saunders Co., Philadelphia.

9. Gissmann, L., E.-M. de Villiers, and H. zur Hausen. 1982. Analysis of human genital warts (condylomata acuminata) and other genital tumors for human papillomavirus type 6 DNA. Int. J. Cancer 29:143-146.
10. Gissmann, L., V. Diehl, H.-J. Schultz-Coulon, and H. zur Hausen. 1982. Molecular cloning and characterization of human papilloma virus DNA derived from a laryngeal papilloma. J. Virol. 44:393-400.

11. Gissmann, L., and A. Schneider. 1986. Human papillomavirus DNA in preneoplastic and neoplastic genital lesions. In H. zur Hausen and R. Peto (ed.), Origins in female genital cancer. Virological and epidemiological aspects. Banbury conference. Cold Spring Harbor Laboratory, Cold Spring Harbor, N.Y.

12. Gissmann, L., L. Wolnik, H. Ikenberg, U. Koldovsky, H. G. Schnürch, and H. zur Hausen. 1983. Human papillomavirus types 6 and 11 DNA sequences in genital and laryngeal papillomas and in some cervical cancers. Proc. Natl. Acad. Sci. USA 80:560-563.

13. Hull, M. T., J. N. Eble, J. B. Priest, and J. J. Mulcahy. 1981. Ultrastructure of Buschke-Löwenstein tumor. J. Urol. 126:485-489.

14. Kreider, J. W., M. K. Howett, S. A. Wolfe, G. L. Bartlett, R. J. Zaino, T. V. Sedlacek, and R. Mortel. Morphological transformation in vivo of human uterine cervix with papillomavirus from condylomata acuminata. Nature (London) 317:639-641.

15. Lehn, H., T.-M. Ernst, and G. Sauer. 1984. Transcription of episomal papillomavirus DNA in human condylomata acuminata and Buschke-Löwenstein tumours. J. Gen. Virol. 65:2003-2010.

16. Maxam, A. M., and W. Gilbert. 1980. Sequencing end-labeled DNA with base-specific chemical cleavages. Methods Enzymol. 65:499-560.

17. Schmauz, R., M. Findlay, A. Lalwack, N. Katsumbira, and E. Buxton. 1977. Variation in the appearance of giant condyloma in a Ugandan series of cases of carcinoma of the penis. Cancer 40:1686-1696.

18. Schwarz, E., M. Dürst, C. Demankowski, O. Lattermann, R. Zech, E. Wolfsberger, S. Suhai, and H. zur Hausen. 1983. DNA sequence and genome organization of genital human papillomavirus type 6b. EMBO J. 2:2341-2348.

19. Watanabe, S., E. Soeda, S. Uchida, and K. Yoshiike. 1984. DNA rearrangement affecting expression of the BK virus transforming gene. J. Virol. 51:1-6.

20. Watanabe, S., Y. Yogo, and K. Yoshiike. 1984. Expression of viral early functions in rat $3 \mathrm{Y} 1$ cells infected with human papovavirus BK. J. Virol. 49:78-85.

21. Watanabe, S., and K. Yoshiike. 1982. Change of DNA near the origin of replication enhances the transforming capacity of human papovavirus BK. J. Virol. 42:978-985.

22. zur Hausen, H. 1982. Human genital cancer: synergism between two virus infections or synergism between a virus infection and initiating events. Lancet ii:1370-1372. 